\title{
Dr. Michael Schmid becomes Coeditor of this Journal and two new Associate Editors have been added
}

The Publishers and I are very pleased to announce that Dr. Michael Schmid of the Biocenter of the University of Würzburg, Germany, has agreed to share the chief editorship of this Journal with me. Dr. Schmid has been a highly effective Associate Editor for this Journal since 1992.

As this journal has continued to grow, the editorial workload has become considerable. Consequently, the addition of another chief editor and two additional associate editors has become essential. We are therefore also very pleased that Dr. Thomas Haaf of the Max-Planck-Institute of Molecular Genetics in Berlin has agreed to become the Associate Editor for the Comparative Cytogenetics section, and that Dr. Bernhard H.F. Weber of the Institute of Human Genetics of the Biocenter of the University of Würzburg has agreed to become the Associate Editor for the new section Genes and Diseases.

In the future authors located in the Eastern Hemisphere of the world are requested to send their manuscripts directly to Dr. Schmid, whereas those located in the Western Hemisphere should continue to send their papers to the New York editorial office. Japanese authors should, however, continue to send their papers to New York.

Gene mapping reports should also be sent to the New York office. On the other hand, animal cytogenetic, including comparative genetic and cytogenetic papers, should all be sent directly to Dr. Schmid, irrespective of the author's geographic location.

We are very pleased that Drs. Schmid, Haaf and Weber have agreed to assume these tasks and we all look forward with great pleasure to working with them.

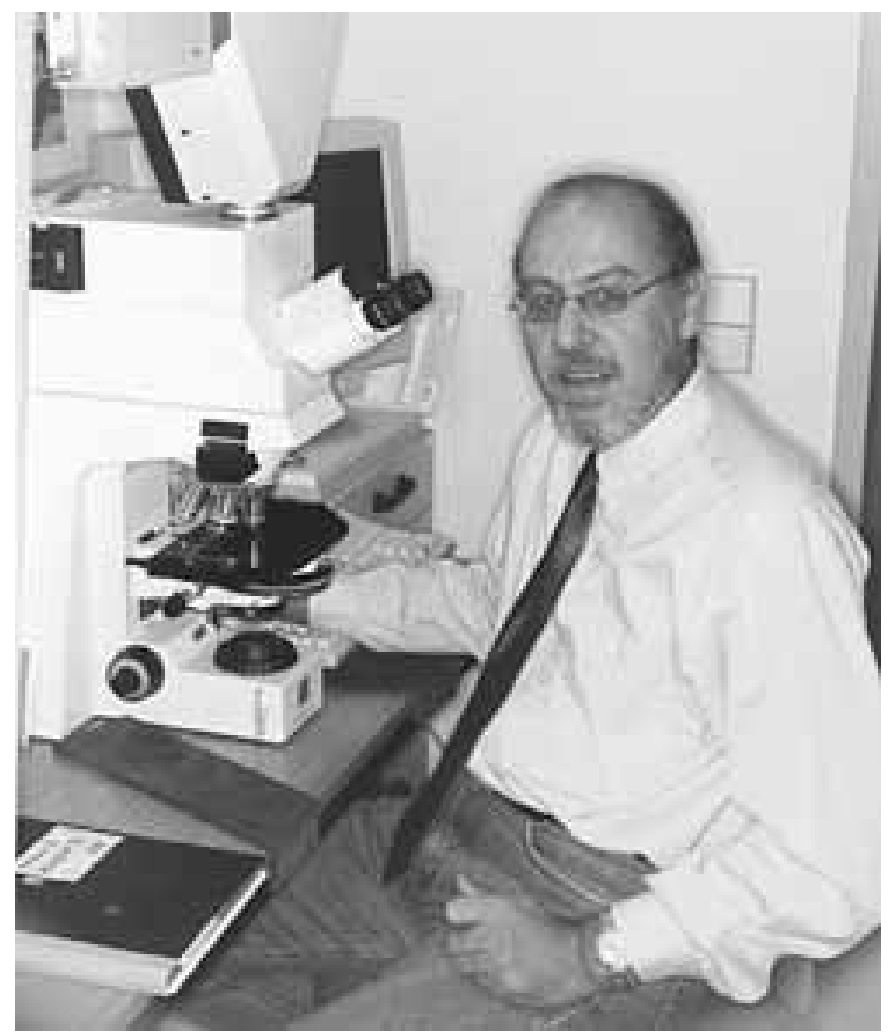

Harold P. Klinger 